DOI: 10.12731/2658-4034-2020-5-67-79

УДК 37.014.54

\title{
РАЗВИТИЕ ПОДРАСТАЮЩЕГО ПОКОЛЕНИЯ В КОНТЕКСТЕ ЦИФРОВИЗАЦИИ
}

\section{Пари О.С.}

Данная статья посвящена актуальному вопросу развития подрастающего поколения в контексте ичирровизации, поскольку глобальная цุифровизация влияет на все стороны развития человеческого общества. Подрастающее поколение очень восприимчиво и с готовностью принимает данные инновации, поэтому молодежь находится в ичентре внимания в период ичифрового обновления общества. Целью данной статьи стало рассмотреть психологопедагогические аспекты, спрогнозировать трудности развития детей и молодежи в условиях ияифровизациии.

Методология и результаты. В исследовании использовался метод педагогического прогнозирования. Анализ современных исследовательских позиций, нормативных документов, регулирующзих изменения в образовании, новый обобщенный опыт позволили сформулировать предполагаемье риски и противоречия развития подрастающего поколения. Говорить о них важно вначале цчифровизации, чтобы избежать или предложить решения. Автор акиентирует внимание на том, что в ходе цицрового обновления общества нужно учитывать особенности взросления подрастающего поколения людей, целенаправленно использовать возможности циифровизации на благо детей и молодежи.

Заключение. В выводах отмечается, что прочесс образования молодого поколения в цифровом обществе должен раскрывать смысль жизни человека, способствовать осознанию возможностей для саморазвития и приобретению опьта деятельности, включая общение и взаимодействие с другими людьми. Цифровые технологии необходимо встраивать в жизнь человека, ведущие 
цุенности развития человека должны быть основой для внедрения циифровизации. Траектория развития человеческого общества в контексте будущего и философия отношения к человеческому потенцииалу подрастающего поколения зависит от нашего выбора сегодня.

Ключевые слова: ичифровизация; развитие; образование; подрастающее поколение; человеческое общество; контекст будущего.

\section{DEVELOPMENT OF THE YOUNGER GENERATION IN THE CONTEXT OF DIGITALISATION}

\section{Parts O.S.}

This article focuses on the topical issue of younger generation development in the context of digitalization, because global digitalization affects all aspects of the development of human society. The younger generation is very receptive and readily accepting these innovations, therefore, young people are at the middle of attention of the digital renewal of society. The purpose of this article was to examine the psychological and pedagogical aspects, and to predict the developmental difficulties of children and young people in the conditions of digitalisation.

Methodology and results. The study used the method of pedagogical forecasting. The analysis of modern research positions, normative documents regulating changes in education, new generalized experience allowed us to formulate the expected risks and contradictions of the development of the younger generation. It is important to talk about them at the beginning of digitalization in order to avoid or offer solutions. The author emphasizes that it is necessary to take into account the peculiarities of growing up of the younger generation of people in the digital renewal process of society, and also to use the possibilities of digitalization purposefully for the benefit of children and young people.

Conclusion. The article notes that the process of education of the young generation in a digital society should reveal the meanings of a person's life, promote awareness of opportunities for self-development and gain 
experience in activities, including communication and interaction with other people. Digital technologies must be integrated in a person's life, the leading values of human development must be the basis for the implementation of digitalization. The trajectory of development of the human society in the context of future and the philosophy of attitudes towards the human potential of the people younger generation depend from our choice today.

Keywords: digitalization; development; education; younger generation; human society; context of the future.

\section{Введение}

Цифровизация, происходящая в современном обществе, затрагивает все стороны развития данного общества, в том числе граждан юного возраста, то есть наших детей. Эпоха цифровизация открывает совершенно новые горизонты для раскрытия и развития возможностей человеческого потенциала: в 21 веке владение информационными технологиями может расцениваться, как умение читать, считать и писать, и от качества этих умений будет зависеть качество жизни человека. Массовая цифровизация неизбежно окажет влияние на все социальные институты общества, в том числе и образование. В центре проблем окажется и уже оказывается молодое поколение, поэтому реализовывать идеи цифровизации в человеческом обществе необходимо с учетом особенностей подрастающего поколения людей - иные аспекты этически не состоятельны.

Вопросам цифровизации в современном обществе посвящены ряд работ современных исследователей, в которых рассматриваются разные аспекты развития общества в эпоху активного внедрения инноваций и цифровизации.

Так, Иванов С.А. формулирует проблемы развития человеческого потенциала в условиях информационного общества [2].

Куликовская И.Э. обращает внимание на важность использования детьми цифровых технологий, робототехники как значимых культурных практик для развития навыков, необходимых им в будущем [15].

Григорьев А.В. акцентирует внимание на социальных рисках цифровизации образования, способных заменить живое общение 
виртуальным и оказать влияние на характер общения и взаимодействия в человеческом обществе [1].

Халин В.Г., Чернова Г.В. исследуют влияние цифровизации на экономическое и социальное развитие общества с точки зрения преимуществ и вызовов, которые требуют своего решения [10].

Шацкая И.В. и Архипов А.И. формулируют возникающие под влиянием цифровизации экономики и социальной сферы направления возможных изменений в сфере образования [12].

Нуреев Р.М. и Карапаев О.В. анализируют основные направления развития цифровых технологий, их влияние на благосостояние человеческого общества, а также формулируют возникающие задачи и проблемы в ходе цифровизации [7].

Каменский Е.Г. и Гримов О.А. отмечают недостаточность диалога с обществом о проблемах цифровизации [14].

Петров А.А. отмечает разные стороны воздействия цифровой экономики на повышение благосостояния и рынок труда [8].

Листвина Е.В. рассматривает риски цифрового общества, оказывающие влияние на современное существование и ближайшее будущее общества [4].

Предметом данной статьи является рассмотрение влияния цифровизации на развитие подрастающего поколения, психолого-педагогических аспектов, которые необходимо учитывать, разрабатывая и внедряя в жизнь современные технологические решения в работе с подрастающим поколением в контексте будущего.

\section{Методология и результаты}

Методология исследовательского поиска основана на анализе современных исследовательских позиций и методе педагогического прогнозирования в ходе обобщения изученного материала и полученного исследовательского опыта.

Под цифровизацией в узком смысле, по Халину В.Г., понимается «преобразование информации в цифровую форму, которое в большинстве случаев ведет к снижению издержек, появлению новых возможностей и т. д.» [10]. 
Цифровая среда отличается от реальной, и одной из ее особенностей является виртуализация среды обитания человека. Что означает это для ребенка, который не имеет опыта сравнения реального и идеального, правильного и ошибочного, должно явиться для взрослого сообщества серьезным вопросом.

Во-первых, нужно учитывать, что дети очень восприимчивы к инновациям технического характера, значительно облегчающим нашу жизнь, в то время как развитие ребенка происходит в непосредственной его деятельностной активности, предполагающей реальное взаимодействие людей, создание продуктов деятельности в реальном общении, сотворчестве в процессе определенного, часто достаточно продолжительного отрезка времени. Каждый человек от природы обладает определенным потенциалом, который проявляется у каждого человека по-разному, носит ярко выраженный индивидуальный характер. Проявление потенциала личности, по Холодной М.А., зависит от среды, в которой происходит развитие ребенка в период взросления и становления [11].

Во-вторых, в силу ограниченности жизненного опыта ребенок принимает все на веру, его легко запутать и ввести в заблуждение. Процесс воспитания молодого поколения в новой виртуальной, весьма противоречивой реальности должен раскрывать сущность реальной жизни человека в обществе, осознания его возможностей для саморазвития и путей приобретения необходимого опыта, в том числе взаимодействия с другими людьми.

В-третьих, современное общество находится в начале пути, и, как показывает практика, не вполне созрело духовно для использования достижений науки и техники, во многом видит в них средства организации свободного времени и развлечений, чем преподносит негативный опыт, как значимый, подрастающему поколению (Маслоу А., 2013) [5]. Поэтому очень важно определиться с целевыми ориентирами цифровизации, определением ценностей реальной жизни, на которые будет работать экономика цифрового общества, и от которых будет зависеть направленность воспитания молодого поколения. 
В-четвертых, цифровизация является очередным шагом в суперсовременное будущее, наполненное новыми технологиями и возможностями. Распространение и внедрение новшеств всегда сопровождается появлением определенных проблем у людей разных возрастов, в том числе и молодежи, на чем акцентирует внимание Иванов С.А., что связано с их освоением, переосмыслением имеющихся возможностей относительно сложившихся традиций в обществе и перспектив человека [2]. Для человека, по Кузнецову Н.В, это может означать снижение количества рабочих мест и усиление конкуренции на рынке труда [3].

Снизить остроту проблемы можно при условии кардинального обновления экономики и всего уклада общественной жизни, на что требуется значительное количество времени, так как речь идет о культурном скачке, трансформации в сознании огромного количества людей отношения ко многим аспектам жизни человека. То есть, мы пытаемся готовить людей, в том числе молодежь к жизни в цифровой реальности, но слабо понимаем, как люди разных поколений будут в ней взаимодействовать: уже прослеживается тенденция разрыва поколений, принижения значимости и уважения молодежи к поколению более взрослых людей, что разрушает преемственность поколений.

Стоит также задуматься, какие ценности трудовой деятельности являются для нас главным. Например, значимость продукта для человека или для производителя, массовость или эксклюзивность выполнения и т.д. На данном этапе освоения новейших технических ресурсов очевидно, что в обществе нет единой позиции относительно перспектив их использования, а также готовности и возможностей повышения квалификации в данной сфере. Можно сказать, что развитие цифровых ресурсов может стать чертой для разделения общества, в том числе и разных поколений, владеющих или не владеющих современными информационными технологиями на должном уровне в эпоху искусственного интеллекта.

В «Национальной стратегии развития искусственного интеллекта» на период до 2030 года приводится следующее определение искусственно- 
го интеллекта: это «комплекс технологических решений, позволяющий имитировать когнитивные функции человека (включая самообучение и поиск решений без заранее заданного алгоритма) и получать при выполнении конкретных задач результаты, сопоставимые, как минимум, с результатами интеллектуальной деятельности человека» [6].

Искусственный интеллект становится частью нашей жизни, при этом свои реальные очертания искусственный интеллект обретает в глазах разных людей совершенно противоположные. С одной стороны, это образец интеллектуальной мысли, способный облегчить жизнь человека: не до конца ясно, где эту жизнь надо облегчить и в каких целях. С другой стороны, идея псевдо свободы человека от труда очень сильно беспокоит человека, особенно взрослого. Молодого человека она расслабляет и дезориентирует, лишая перспективы профессионального развития, поскольку перечень профессий будущего отсутствует, существующие претерпевают изменения, при этом образование не всегда успевает за требованиями времени. Поэтому, обновляя инфраструктуру самого общества, политикам, экономистам, общественникам стоит задуматься о том, какого качества будет создаваемый искусственный интеллект, насколько эти преобразования откроют нашим детям реальные перспективы обретения социальной значимости в обществе.

На пороге третьего десятилетия 21 века мы много говорим о новом витке развития цивилизации, о проблеме духовности подрастающего поколения. Но проблема духовности начинается с реального соблюдения прав и свобод человека, реализации различных потребностей подрастающего молодого поколения.

Необходимо отметить, что для воплощения идей цифровизации в обществе создается нормативная база, начиная с Федерального Закона «Об образовании в Российской Федерации», декларирующего в ст. 16 использование электронного обучения и дистанционных технологий в образовании [9]. На уровне государства также обсуждаются документы, имеющие своей целью расширение возможностей информационной системы и создание современной информационной образовательной среды. Совершенно очевидно, что 
ставка в совершении очередного технологического прорыва современной цивилизации делается именно на наших детей и человеческий интеллект, поскольку искусственный интеллект тоже является технологией, и практически всегда будет требовать к себе внимание со стороны человека в вопросах усовершенствования и обслуживания. Учитывая данные обстоятельства, мы должны понимать, что главное для реализации планов на будущее - это жизнь человека. Человек осознает, что живет, когда развивается духовно и радуется жизни. При этом пресыщение благами жизни доставляет больше неудобств, чем радости. Существует немало примеров, когда богатые и успешные люди возвращаются к простой жизни, не отказываясь при этом от достижений (безусловно, к ним относятся цифровые технологии), которые наряду с книгой, позволяют ощущать себя идущим в ногу со временем и раскрывать многообразие мира.

Возникает также вопрос о характере использования творческого потенциала человека в эпоху цифровизации. В п. 22 «Национальной стратегии развития искусственного интеллекта» находим ответ, что «использование технологий искусственного интеллекта в социальной сфере направлено на создание условий для улучшения уровня жизни населения, в том числе повышение качества услуг в сфере образования (включая адаптацию образовательного процесса к потребностям обучающихся и потребностям рынка труда, системный анализ показателей эффективности обучения для оптимизации профессиональной ориентации и раннего выявления детей с выдающимися способностями)» [6]. Вопрос заключается в том, насколько мы учитываем возрастные особенности ребенка, говоря о его ранней профессионализации, не явится ли это угрозой для омоложения синдрома профессионального выгорания, по Петрову А.А., обострения и без того «нарастающей конкуренции между специалистами разных поколений» [8]. Только здесь речь будет идти о дроблении возрастных групп и обострении конкуренции внутри поколения молодых специалистов в сфере занятости (Huws U., 2014) [13], что будет являться естественным тормозом развития творческого потенциала человека, и, как следствие, цифровой экономики. 


\section{Заключение}

Обобщая наблюдения и формулируя выводы, отметим, что молодое подрастающее поколение человека имеет определенные, данные природой жизненные потребности, среди которых готовность созидать и преобразовывать окружающий мир, а также чисто человеческая потребность дружить, любить и быть любимыми, создавать семьи, растить детей, что возможно осуществить при условии наличия самих условий для простого личностного общения. Это основа созидательной составляющей личности человека, полной творческой силы, наполняющей человеческие отношения красотой и светом, согревающей человека в самые трудные минуты его жизни.

Цифровизация - средство обновления жизни человеческого общества, развитие данного ресурса возможно при концентрации усилий разных поколений людей. В идеальном своем воплощении цифровые технологии призваны помочь подрастающему поколению в развитии, и взрослое поколение несет ответственность за корректность внедрения цифровизации по отношению к детям и молодежи: идеи конкуренции «цифры» и человека этически не корректны и не состоятельны.

Внедрение технологий вторгается в жизнь человека и влияет на него неоднозначно. Развитие человека происходит по определенным законам природы, которые тоже надо учитывать в реальной жизни, реальном времени и пространстве: все инновации воплощают люди, которые поэтапно познают жизнь, также постепенно переосмысливают ее, в ходе преобразований спорят и находят точки согласия. Лишая современное молодое поколение ценностей возраста, мы обкрадываем наше будущее: всю силу своей неудовлетворенности она вложит в создаваемые ей технологии, характер их продвижений и реализации, что не сделает общество богаче и нравственнее. Недооценка психолого-педагогических аспектов развития подрастающего поколения в эпоху цифровизации может привести к искажению развития человека и человеческого общества: подвергается риску качественная составляющая развития и сама цифровая экономика.

Поэтому стоит вдумчиво внедрять цифровые технологии, встраивать их в жизнь человеческого общества, создавая необходимую инфраструктуру; параллельно обновлять содержание образования, 
создавать рабочие места, снимая накал противостояния «цифры» и человека. Аспекты гуманизации развития подрастающего поколения являются жизнеопределяющими в условиях цифровизации общества. Только в этом случае благодаря такой мощной инновации, как цифровизация, человечество сможет осознать необходимость выбора траектории развития будущего человеческого общества на столетия вперед и на этой основе определить философию отношения к человеческому потенциалу подрастающего поколения.

\section{Список литературы}

1. Григорьев А.В. Социальные риски цифровизации школьного образования // Информатизация образования и методика электронного обучения: цифровые технологии в образовании: материалы IV Междунар. науч. конф. Красноярск, 6-9 октября 2020 г.: в 2ч. Ч.2. Красноярск : Сиб. федер. ун-т, 2020. С. 414-419.

2. Иванов С.А. Человеческий потенциал инновационной экономики: проблемы формирования и использования в современной России // Вестник Российской Академии естественных наук. 2015. №3. С. 4147. https://elibrary.ru/item.asp?id=24435519

3. Кузнецов Н.В. Цифровизация экономики России: институционациональные драйверы // Теория и практика общественного развития. 2019. №4(134). С. 75-78. https://elibrary.ru/item.asp?id=37317161

4. Листвина Е.В. Социокультурные риски цифровизации современного общества // Актуальные проблемы гуманитарных и социальноэкономических наук. 2019. №13. С. 78-82. https://www.elibrary.ru/ item.asp?id=37321467

5. Маслоу А.Г. Мотивация и личность / Абрахам Маслоу ; [пер. с англ. Т. Гутман, Н. Мухина]. 3-е изд. Москва: Питер, 2013. 351 с.

6. Национальная стратегия развития искусственного интеллекта на период до 2030 года. Указ Президента РФ от 10.10.2019 N 490. http:// www.consultant.ru/document/cons_doc_LAW_335184/

7. Нуреев Р.М., Карапаев О.В. Три этапа становления цифровой экономики // Journal of Economic Regulation. 2019. T.10. №2. С. 6-27. https://www.elibrary.ru/item.asp?id=38982527 
8. Петров А.А. Цифровизация экономики: проблемы, вызовы, риски // Торговая политика. 2018. №3(5). C. 9-31. https://elibrary.ru/item. asp? $\mathrm{id}=38695381$

9. Федеральный закон от 29.12.2012 г. № 273-Ф3 «Об образовании в Российской Федерации». https:/www.consultant.ru/cons/cgi/ online.cgi req $=$ doc $\&$ base $=$ LAW $\& n=356002 \& d s t=1000000001 \%$ 2C0\#013589787698124267

10. Халин В.Г. Цифровизация и ее влияние на российскую экономику и общество: преимущества, вызовы, угрозы и риски / В.Г. Халин, Г.В. Чернова // Управленческое консультирование. 2018. № 10(118). C. 46-63. https://elibrary.ru/item.asp?id=36399688

11. Холодная М.А. Эволюция интеллектуальной одаренности от детства к взрослости: эффект инверсии развития // Психологический журнал [Электронный ресурс]. 2011. Т. 32. №5. C. 69-78. https://elibrary. ru/item.asp?id=16777861

12. Шацкая И.В., Архипов А.И. Цифровизация экономики и новейшие тенденции в системе образования // Горизонты экономики. 2019. № 2. C. 53-57.

13. Huws U. Labor in the Global Digital Economy: The Cybertariat Comes of Age. N. Y., 2014. 240 p.

14. Kamensky E., Grimov O. Digitalization: public opinion landscapes (on the example of Russia) // Economic Annals - XXI. 2019. N 11-12. C. 48-57. https://www.elibrary.ru/contents.asp?id=43072619

15. Kulikovskaya I., Chumicheva R., Panov I. Robotics: development factor or social isolation of the child // SHS Web of Conferences. Vol. 72. International Scientific Conference: "Achievements and Perspectives of Philosophical Studies”. 2019. DOI: https://doi.org/10.1051/shsconf $/ 20197203008$

\section{References}

1. Grigoriev A.V. Informatizatsiya obrazovaniya i metodika elektronnogo obucheniya: tsifrovye tekhnologii v obrazovanii: materialy IV Mezhdunar. nauch. konf. Krasnoyarsk, 6-9 oktyabrya 2020 g. [Informatization of education and e-learning methods: digital technologies in education: 
materials of the IV Intern. scientific. conf. Krasnoyarsk, October 6-9, 2020]. Part 2. Krasnoyarsk: Sib. Feder. un-t, 2020. P. 414-419.

2. Ivanov S.A. Vestnik Rossiyskoy Akademii estestvennykh nauk [Bulletin of the Russian Academy of Natural Sciences]. 2015. No. 3. P. 41-47. https://elibrary.ru/item.asp?id=24435519

3. Kuznetsov N.V. Teoriya i praktika obshchestvennogo razvitiya [Theory and practice of social development]. 2019. No. 4 (134). P. 75-78. https:// elibrary.ru/item.asp?id=37317161

4. Listvina E.V. Aktual'nye problemy gumanitarnykh i sotsial'no-ekonomicheskikh nauk [Actual problems of the humanities and socio-economic sciences]. 2019. No. 13. P. 78-82. https://www.elibrary.ru/item. asp? $\mathrm{id}=37321467$

5. Maslow A.G. Motivation and Personality [Motivatsiya i lichnost']. Moscow: Peter, 2013. 351 p.

6. Natsional'naya strategiya razvitiya iskusstvennogo intellekta na period do 2030 goda. Ukaz Prezidenta RF ot 10.10.2019 N 490 [National strategy for the development of artificial intelligence for the period up to 2030. Decree of the President of the Russian Federation of 10.10.2019 N 490]. http://www.consultant.ru/document/cons_doc_LAW_335184/

7. Nureyev R.M., Karapaev O.V. Tri etapa stanovleniya tsifrovoy ekonomiki [Three stages of the formation of the digital economy]. Journal of Economic Regulation. 2019. V.10. № 2. P. 6-27. https://www.elibrary. $\mathrm{ru} / \mathrm{item} . \mathrm{asp}$ $\mathrm{id}=38982527$

8. Petrov A.A. Torgovaya politika [Trade Policy]. 2018. No. 3 (5). P. 9-31. https://elibrary.ru/item.asp?id=38695381

9. Federal'nyy zakon ot 29.12.2012 g. № 273-FZ «Ob obrazovanii v Rossiyskoy Federatsii» [Federal Law of December 29, 2012 No. 273-FZ "On Education in the Russian Federation"]. https://www.consultant.ru/ cons/cgi/online.cgi?req $=$ doc $\&$ base $=$ LAW $\& n=356002 \&$ dst $=100000000$ 1\%2C0\#013589787698124267

10. Khalin V.G., Chernov G.V. Upravlencheskoe konsul 'tirovanie [Management consulting]. 2018. No. 10 (118). P. 46-63. https://elibrary.ru/item. asp?id=36399688

11. Kholodnaya M.A. Psikhologicheskiy zhurnal [Psychological journal]. 2011. V. 32. No. 5. P. 69-78. https://elibrary.ru/item.asp?id=16777861 
12. Shatskaya I.V., Arkhipov A.I. Gorizonty ekonomiki [Horizons of the economy]. 2019. No. 2. P. 53-57.

13. Huws U. Labor in the Global Digital Economy: The Cybertariat Comes of Age. N. Y., 2014.240 p.

14. Kamensky E., Grimov O. Digitalization: public opinion landscapes (on the example of Russia). Economic Annals - XXI. 2019. N 11-12. P. 4857. https://www.elibrary.ru/contents.asp?id=43072619

15. Kulikovskaya I., Chumicheva R., Panov I. Robotics: development factor or social isolation of the child. SHS Web of Conferences. Vol. 72. International Scientific Conference: "Achievements and Perspectives of Philosophical Studies”. 2019. DOI: https://doi.org/10.1051/shsconf $/ 20197203008$

\section{ДАННЫЕ ОБ АВТОРЕ}

\section{Парц Ольга Степановна, к.п.н., доцент}

ФГБОУ ВО «Омский государственный педагогический университет»

ул. Набережная им. Тухачевского, 14, г. Омск, Омская область, 644099, Российская Федерациия pobeda57@yandex.ru

\section{DATA ABOUT THE AUTHOR}

Parts Olga Stepanovna, $\mathrm{PhD}$ in Pedagogy, Associate Professor Omsk State Pedagogical University 14, Tukhachevsky Embankment Str., Omsk, Omsk region, 644099, Russian Federation pobeda57@yandex.ru SPIN-code: 4563-3243 